\title{
An Examination of Differences in Psychological Resilience between Social Anxiety Disorder and Posttraumatic Stress Disorder in the Context of Early Childhood Trauma
}

OPEN ACCESS

Edited by:

Alexandre Heeren,

Harvard University, United States

Reviewed by:

Maicon Rodrigues Albuquerque, Universidade Federal de Minas Gerais,

Brazil

Feng Liu,

Tianjin Medical University General Hospital, China

*Correspondence:

Melanie Marx

melaniemarxsa@gmail.com

Specialty section:

This article was submitted to

Psychopathology,

a section of the journal

Frontiers in Psychology

Received: 17 March 2017 Accepted: 13 November 2017 Published: 11 December 2017

Citation:

Marx M, Young SY, Harvey J, Rosenstein D and Seedat S (2017) An

Examination of Differences in

Psychological Resilience between

Social Anxiety Disorder and Posttraumatic Stress Disorder in the Context of Early Childhood Trauma.

Front. Psychol. 8:2058.

doi: 10.3389/fpsyg.2017.02058

\section{Melanie Marx ${ }^{1 *}$, Susanne Y. Young ${ }^{1}$, Justin Harvey ${ }^{2}$, David Rosenstein ${ }^{1}$ and Soraya Seedat ${ }^{1}$}

${ }^{1}$ Psychiatry, Faculty of Medicine and Health Sciences, Stellenbosch University, Cape Town, South Africa, ${ }^{2}$ Department of Statistics and Actuarial Science, Faculty of Economics and Management Sciences, Stellenbosch University, Stellenbosch, South Africa

Background: Much of the research on anxiety disorders has focused on associated risk factors with less attention paid to factors such as resilience that may mitigate risk or offer protection in the face of psychopathology.

Objective: This study sought to compare resilience in individuals with posttraumatic stress disorder (PTSD) and social anxiety disorder (SAD) relative to age-, gender- and education- matched individuals with no psychiatric disorder. We further assessed the correlation of resilience scores with childhood trauma severity and type.

Method: The sample comprised of 93 participants, 40 with SAD with childhood trauma), 22 with PTSD with childhood trauma, and 31 with no psychiatric disorder (i.e., healthy matched controls). Participants were administered the Mini-International Neuropsychiatric Interview (MINI), Liebowitz Social Anxiety Scale (LSAS), Clinician-Administered PTSD Scale (CAPS), Childhood Trauma Questionnaire-Short Form (CTQ-SF), and the Connor-Davidson Resilience Scale (CD-RISC). The mean age of participants was 34 years (SD =11). 52 Participants were female (55.9\%) and 54 Caucasian (58.1\%). Analysis of variance was used to assess for significant group differences in resilience scores. Non-parametric correlation analyses were conducted for resilience and different types of childhood trauma.

Results: There were significant differences in resilience between the SAD and PTSD groups with childhood trauma, and controls. Both disorder groups had significantly lower levels of resilience than healthy controls. No significant correlation was found between total resilience scores and childhood trauma scores in the childhood trauma (SAD and PTSD) groups. However, in the combined dataset (SAD, PTSD, healthy controls), significant negative correlations were found between resilience scores and emotional abuse, emotional neglect, and total childhood trauma scores.

Conclusions: Patients who have PTSD and SAD with childhood trauma appear to be significantly less resilient than those with no disorder. Assessing and addressing resilience in these disorders, particularly when childhood trauma is present, may facilitate long-term recovery and warrants further investigation.

Keywords: social anxiety disorder, posttraumatic stress disorder, physical neglect, physical abuse, emotional abuse, sexual abuse, childhood trauma, resilience 


\section{INTRODUCTION}

Childhood trauma is a significant etiological precursor for the development of psychopathology (Kendler et al., 1995; Agid et al., 2000; Heim and Nemeroff, 2001; Spila et al., 2008). Childhood trauma is defined as any traumatic experience occurring before the age of 18 and is categorized into five subtypes, namely emotional abuse, emotional neglect, physical abuse, physical neglect, and sexual abuse (Bernstein et al., 1997). Several retrospective studies indicate that early exposure to trauma is associated in adulthood with an increased risk of developing anxiety and stress-related disorders (Kendler et al., 1995; Agid et al., 2000; Heim and Nemeroff, 2001; Spila et al., 2008), including posttraumatic stress disorder (PTSD) (Ballenger et al., 2004; Bandelow et al., 2004; Etkin and Wager, 2007; Yehuda et al., 2010) and social anxiety disorder (SAD), (Heim and Nemeroff, 2001; Fossion et al., 2014), and an elevated stress response to mild stressors (Nemeroff, 2004). Norman et al. (2012) documented a significant association between childhood physical abuse, and emotional abuse and neglect, and anxiety disorders; see Carr et al. (2013) for a review on the associations between childhood abuse (physical abuse and neglect, emotional abuse and neglect, sexual abuse) and anxiety disorders. Specifically, a significant relationship has been observed between physical abuse (Norman et al., 2012) and sexual abuse in childhood and PTSD (Kendler et al., 1995). In addition, multiple trauma exposures in early life have been linked to increased PTSD symptoms (Collin-Vézina et al., 2011). Suliman et al. (2009) found that adolescents who experienced numerous childhood adversities were more likely to experience increased severity of their PTSD symptoms. In adults, Simon et al. (2009) documented greater disorder severity in individuals with the generalized subtype of SAD who also had childhood maltreatment.

However, not all individuals who experience childhood adversities develop PTSD, SAD or other psychopathology as adults (Collishaw et al., 2007) and may be regarded as possessing resilience characteristics that protect them from developing psychopathology. This resilience may present as capacities that engender adaptation after trauma exposure. Resilience lies on a continuum ranging from well-adapted (and highly resilient) to maladapted (and prone to psychiatric disorders) (Ehlert, 2013). Resilience is the ability to cope after a trauma/stressor (Masten et al., 1999; Masten, 2001; Connor and Davidson, 2003; Tusaie and Dyer, 2004). Resilience is further defined as a set of individual characteristics that may offer coping/protection when faced with trauma (Hoge et al., 2007). These characteristics include a certain way of perceiving, or a pattern of thinking and/or decision making, in reaction to different traumas (Agaibi and Wilson, 2005). Several factors have been associated with resilience, namely an internal locus of control, a sense of meaning, a strong self-esteem, and good problem-solving skills (Rutter, 1985; Taylor et al., 2000; Masten et al., 2009).

In this paper we refer to resilience as a measure of the ability to cope after a trauma/stressor, as described by Connor and Davidson (2003). The Connor-Davidson Resilience Scale (CD-RISC) assesses personal competence, high standards, and instincts; capability of enduring negative emotional experiences; positive acceptance of change and secure relationships; control and spiritual influences (Connor and Davidson, 2003). A trauma or stressor may disrupt the biopsychospiritual homeostasis of an individual. Connor and Davidson (2003) explain that there can be four reactions to a trauma/stressor. First, the trauma/stressor may present the person with an opportunity to grow, increase their resilience, and thereby facilitate return to a higher level of homeostasis. Second, the person may move forward and slightly beyond the trauma/stressor, resulting in a return to baseline homeostasis (as it was before the trauma/stressor). Third, the person may overcome the stressor but return to a lower level of homeostasis. Lastly, the person may maladjust and use destructive means to cope with the trauma/stressor (Connor and Davidson, 2003). The recent shift in focus away from pathology and problem orientation to health promotion has resulted in more awareness of the importance of resilience to wellness (Bonanno, 2004).

Simon et al. (2009) hypothesized that childhood trauma (as measured with the total CTQ score) may be associated with less resilience. Specifically, emotional neglect was associated with less resilience in adults with SAD (Simon et al., 2009). Simeon et al. (2007) found that childhood trauma was significantly negatively correlated with resilience in healthy adults. However, contrary to these findings, DuMont et al. (2007) assessed, among other variables, childhood abuse, childhood neglect and resilience in 676 adults and found that individuals who had experienced adversities and stressful life events were more resilient. This is supported by other studies that have shown that in the face of childhood trauma, including childhood sexual abuse (CSA), some individuals are able to positively adapt and grow (Luther and Cicchetti, 2000; Bonanno, 2004; Wright et al., 2005). Valentine and Feinauer (1993) assessed 57 women who had experienced CSA but were functioning well as adults. Factors that contributed to their well-being as adults included the ability to see that they were the victims, not feeling responsible for the abuse, and developing a sense of purpose. These findings underscore the importance of examining resilience in relation to childhood trauma in the etiology of SAD. In a study by Himelein and McElrath (1996), no differences were documented between a traumatized group who experienced CSA and non-victimized controls, in terms of the overall level of adjustment. In addition, Rutter (2007) suggested that childhood trauma may increase resilience in adulthood, even in the presence of a mental disorder. This phenomenon can be explained by "stress innoculation theory" which posits that a toughening in physiology occurs (Rutter, 1987), with the experience of childhood trauma in some individuals contributing to their being less affected by stressors in adulthood (Campbell-Sills et al., 2006). It has also been found that increased traits of resilience may ameliorate PTSD symptoms, in individuals who have suffered childhood abuse and neglect (Fincham et al., 2009). In addition, a study by Campbell-Sills et al. (2006) found those individuals who had higher levels of childhood emotional neglect also showed greater symptom severity, but only if they were less resilient. In other words, of all participants, those who reported high levels of childhood emotional neglect and high levels of resilience, scored lowest on psychiatric symptoms (Campbell-Sills et al., 2006). 
Among South Africans, anxiety disorders are the most prevalent of lifetime mental disorders at $15.8 \%$, with SAD and PTSD at 2.8 and 2.3\%, respectively (Herman et al., 2009). Resilience may be a valuable tool in the treatment of adult individuals with anxiety (Connor and Davidson, 2003) and especially in those who have faced past trauma. In addition, Collishaw et al. (2007) have suggested that our understanding of how abuse affects psychosocial development may be enhanced by our understanding of resilience. Furthermore, a systematic review on child abuse and neglect concluded that more studies should research elements that may contribute to resilience (Kaplan et al., 1999). There has been little investigation of resilience in adults with an anxiety disorder and early childhood trauma exposure, moreover in SAD and PTSD. It is plausible that childhood trauma may interact with the degree of resilience in adult individuals with PTSD and SAD. Resilience, as measured by the CD-RISC, has been shown to mitigate depressive symptom severity in adults, as contributed to by childhood abuse and other traumas (Wingo et al., 2010). However, to our knowledge there are no studies that have assessed resilience in PTSD and SAD in the context of childhood trauma. This is important given that resilience, against a background of childhood trauma, may be a modifiable target for treatment recovery in patients with anxiety disorders.

We hypothesized that there would be significant differences in resilience among adults with PTSD secondary to childhood trauma, adults with SAD and childhood trauma, and a control group without childhood trauma, PTSD or SAD. Second, we hypothesized that resilience scores would be negatively correlated with childhood trauma scores (physical and emotional neglect and abuse, and sexual abuse) in adults with PTSD and SAD. Thirdly, when combining all groups (PTSD, SAD, and controls), we hypothesize that due to the inclusion of the control group in this analyses, a negative relationship would be found between different childhood traumas and resilience.

\section{METHOD}

\section{Design}

We undertook a cross-sectional analysis of data from a larger imaging-genetics study of SAD and PTSD.

\section{Participants}

Participants were recruited from community clinics, hospitals, non-governmental organizations (NGOs) and other psychiatric institutions in Cape Town, South Africa, using convenience sampling. At these sites, the study was advertised via pamphlets, emails, or visual electronic representations on plasma screens. The study included a total of 93 participants, 40 with current SAD with childhood trauma (moderate/severe), 22 with current PTSD secondary childhood trauma (moderate/severe) (further referred to as SAD and PTSD, respectively), and 31 with no psychiatric disorder and no childhood trauma (i.e., healthy controls).

The mean age of participants $(N=93)$ was 34 years $(S D$ $=11$; range of $20-72$ years). Most were female $(55.9 \%, n=$ 52), Caucasian (58.1\%, $n=54), 25.8 \%(n=24)$ of mixed race [Colored], Black (12.9\%, $n=12)$, Asian $(2.2 \%, n=2)$, and other
$(1.1 \%, n=1) .52$ were single $(55.9 \%)$, married $(23.7 \%, n=22)$, living with a partner $(11.8 \%, n=11)$, divorced $(6.5 \%, n=6)$ or widowed $(2.2 \%, n=2)$. The majority were employed $(63.4 \%, n=$ $59)$, had 12 or more years of education $(83.8 \%, n=78)$, and had an annual household income of more than R60 000 per annum $(\$ 6,000)(76.3 \%, n=71)$.

Participants were assessed with the Social Anxiety Scale (LSAS), Clinician-Administered PTSD Scale (CAPS), Childhood Trauma Questionnaire-Short Form (CTQ-SF, further referred to as the CTQ), Connor-Davidson Resilience Scale (CD-RISC), and the Mini International Neuropsychiatric Interview (MINI) version 6.0 (Sheehan et al., 1998) to determine whether they met inclusion criteria for one of the three groups. These assessments were administered by a clinical psychologist. On the basis of this screening, participants were categorized into the following groups: PTSD, SAD, and controls. Both right and left handed participants were included and were carefully matched across groups and handedness was accounted for in all statistical analyses. Other exclusion criteria included the following Axis I disorders: all DSM-IV psychotic disorders, bipolar mood disorders, obsessive-compulsive disorder, eating disorders and current alcohol or substance abuse or addiction disorders. Other Axis one disorders were only included if in remission or if not established as the principal presenting complaint on the MINI. All neurological disorders, included head injuries with a loss of consciousness at any point in life, counted as exclusion from the study. Other criteria for exclusion included reported drug abuse/dependence or alcohol abuse/dependence within the past 6 months (Cooney et al., 2006). Subjects were excluded if they were currently taking psychotropic medication, besides an SSRI. Due to the fMRI scanning component of the main study, participants were excluded if they also had a cardiac pacemaker, metal prosthesis or pin(s), clips on blood vessels, inner ear prosthesis, an infusion pump, a metal intra-uterine contraceptive device or they were currently pregnant. All metal objects and jewelry were removed before any scanning. With regard to the PTSD group, only participants with a diagnosis of PTSD that was secondary to childhood trauma were included, hence participants with PTSD secondary to adult-onset trauma were excluded.

\section{Measures \\ Diagnostics}

SAD, PTSD and other psychiatric disorders were assessed with the MINI (Sheehan et al., 1998), based DSM-IV-R criteria (American Psychiatric Association, 2000). The MINI has good inter-rater and test-retest reliability (Lecrubier et al., 1997). Participants with psychotic disorders, personality disorders, neurological disorders, drug abuse/dependence (prescription and/or other) and alcohol abuse/dependence were excluded. Controls had no psychiatric disorders as assessed with the MINI and no childhood trauma exposure (as determined by a cutoff score of below 40 on the CTQ). For the purpose of MRI investigation, participants currently on psychotropic medication (with the exception of an SSRI), with a cardiac pacemaker, metal prosthesis or pin(s), clips on blood vessels, inner ear prosthesis, an infusion pump, a metal intra-uterine contraceptive device or pregnancy were excluded. 


\section{Social Anxiety Disorder}

The LSAS is clinician-administered and consists of 24 questions (Baker et al., 2002), each on a 4-point Likert Scale. The cut-off score for clinically significant social anxiety is 60 (Safren et al., 1999), and is also used to discriminate between generalized and specific SAD (Baker et al., 2002). Examples of items include: "telephoning in public," "writing while being observed," and "meeting strangers." A psychometric evaluation of the LSAS has shown good test-retest reliabilities of the total score $(r=0.83, p$ $<0.01)$ and fear/anxiety and avoidance sub scores $(r=0.79, p$ $<0.01$, and $r=0.83, p<0.01$, respectively) (Baker et al., 2002). Cronbach alphas for the LSAS total score for this sample was 0.96 . For the subscales, Cronbach alphas were 0.94 for fear/anxiety and 0.93 for avoidance, respectively.

\section{Posttraumatic Stress Disorder}

PTSD diagnosis was assessed with the CAPS. The CAPS can be used to identify current or lifetime PTSD. Cross-cultural research shows that the CAPS has high reliability with a coefficient alpha of 0.92 and strong convergent validity with instruments measuring depression, anxiety and levels of psychosocial functioning (Charney and Keane, 2007). Events include, amongst others, "natural disasters," "fire or explosion," and physical assault." Participants are asked to check the appropriate boxes for each event, namely "happened to me," "witnessed it," "learned about it," "not sure," or "doesn't apply." Frequency and intensity scores can also be determined (Blake et al., 1990; Weathers et al., 2001).

\section{Childhood Trauma}

The CTQ is a retrospective self-report questionnaire of childhood trauma consisting of 28 items (i.e., trauma before the age of 18) (Bernstein and Fink, 1998). This scale measures five types of childhood trauma, namely physical abuse and neglect, sexual abuse, and emotional abuse and neglect (Bernstein and Fink, 1998). No trauma was indicated if a participant had a score of less than 40. To make a clear distinction between traumatized and non-traumatized individuals, all participants with scores between 41 and 46 were excluded (Bernstein et al., 1997). A score above 46 was used to delineate moderate/severe trauma (Bernstein and Fink, 1998). The CTQ has been found to have an internal consistency of 0.91 (Cronbach alpha). Furthermore, it has demonstrated good reliability: test-retest reliabilities ranging from 0.79 to 0.86 and internal consistency reliabilities ranging from a median of 0.66 for the physical neglect subscale to a median of 0.92 for the sexual abuse subscale (Bernstein and Fink, 1998). Moreover, results from a sample of racially mixed individuals showed internal consistency reliability rates for the entire measure (0.91) and four of the subscales. Within the current sample, the internal reliability (Cronbach alpha) of the CTQ total scale was 0.85 . Cronbach alphas for the CTQ subscales were as follows: emotional Abuse (0.87), physical abuse ( 0.84 ), sexual abuse (0.91), emotional neglect (0.90), and physical neglect (0.67). Items include "I didn't have enough to eat," "people in my family said hurtful or insulting things to me," "someone molested me," and "I had to wear dirty clothes."

\section{Resilience}

Resilience was measured with the CD-RISC (Connor and Davidson, 2003). The CD-RISC is a self-report questionnaire that consists of 25 items. The scale asks participants about how much they agree with each statement, or if the situation has not occurred recently, and how they think they felt during the last month. Participants rate themselves on a 5-point Likert scale (ranging from $0=$ "not at all true," to $4=$ "true nearly all of the time") according to how much they agree or disagree with each statement (e.g., I am able to adapt when changes occur). The CD-RISC measures five constructs of resilience: firstly, personal competence and high standards; secondly, a person's instincts, person's capability of enduring negative emotional experiences; thirdly, positive acceptance of change and relationships that are secure. The fourth construct refers to control and the last to spiritual influences that may contribute to resilience. Psychometric evaluation of the CDRISC conducted on clinical and general population samples found the scale to have good reliability (Cronbach $\alpha=0.89$ ), validity, psychometric properties, good internal consistency and test-retest reliability ( $r=0.87$ ) (Connor and Davidson, 2003). Within the current sample, the internal reliability (Cronbach alpha) of the CD-RISC was 0.94. Examples of items include the following: "I am able to adapt when changes occur," "I tend to bounce back after illness, injury, or other hardships," and "I give my best effort, no matter what the outcome may be." The total CD-RISC scale is made up out of 5 factors. The reliability of these subscales in this sample was good: Factor 1; notion of personal competence, high standards, and tenacity ( $r$ $=0.90)$, Factor 2; trust in one's instincts, tolerance of negative affect, and strengthening effects of stress $(r=0.82)$, Factor 3; positive acceptance of change, and secure relationships $(r=0.76)$, Factor 4 ; control $(r=0.84)$, Factor 5 ; spiritual influences $(r=$ $0.64)$.

\section{Ethical Considerations}

The study received approval from Stellenbosch University's Health Research Ethics Committee (HREC, Ethics number: N09/09/226, latest approval: 04/05/2014). Written informed consent was obtained from all participants by a clinical psychologist prior to the initiation of study procedures and participants were reimbursed for travel costs. A clinical psychologist judged whether participants were able to understand the aims and risks of the study and be able to provide written informed consent.

\section{Data Analyses}

The resilience total (CD-RISC) scores and separate resilience factor scores were normally distributed. Analysis of variance (ANOVA), followed by post-hoc Bonferroni testing, was undertaken to assess differences in resilience scores among the groups (SAD, PTSD, healthy controls). The CTQ total and subscale scores were not normally distributed. Non-parametric correlational analysis (Spearman's tests) of CD-RISC and CTQ subscale scores was performed for (1) PTSD and SAD $(n=62)$ and PTSD, SAD and Control $(n=92)$ groups. All tests were two-tailed and the significance level for Spearman's test was set 
at $p=0.0083(0.05 / 6)$. All statistical analyses were conducted using IBM SPSS Statistics for Windows, Version 22.0. IBM Corp. Released 2013. Armonk, NY: IBM Corp. For an overview of the demographics and clinical data see Table 1. For an overview of the group means and standard deviations of the questionnaires see Table 2. For an overview of the ANOVA and post-hoc results see Tables 3, 4. For an overview of the correlations see Tables 5, 6.

TABLE 1 | Demographic and clinical data.

\begin{tabular}{|c|c|c|c|c|c|c|c|}
\hline \multirow[t]{2}{*}{$N=93$} & & \multicolumn{2}{|c|}{$\begin{array}{c}\text { SAD + } \\
(n=40)\end{array}$} & \multicolumn{2}{|c|}{$\begin{array}{c}\text { PTSD } \\
+ \\
(n=22)\end{array}$} & \multicolumn{2}{|c|}{$\begin{array}{c}\text { HC } \\
(n=31)\end{array}$} \\
\hline & & $M$ & sd & $M$ & sd & $M$ & sd \\
\hline Age (y) & & 36.6 & 12.6 & 35.5 & 11.5 & 30 & 7.4 \\
\hline Gender (Males \%) & & 45 & & 40.9 & & 45.2 & \\
\hline Years of education $(y)^{a}$ & & 14 & 2.3 & 12.8 & 3.4 & 15.8 & 3 \\
\hline \multirow[t]{5}{*}{ Ethnicity (\%) } & African & 10 & & 22.7 & & 9.7 & \\
\hline & Mixed race & 30 & & 36.4 & & 12.9 & \\
\hline & Caucasian & 55 & & 40.9 & & 74.2 & \\
\hline & Asian & 2.5 & & & & 3.2 & \\
\hline & Other & 2.5 & & & & & \\
\hline
\end{tabular}

Results of sample; SAD+, Social anxiety with CHT; PTSD+, Posttraumatic stress disorder secondary to $\mathrm{CHT}$; HC, Healthy controls. Demographic characteristics are presented in the first few rows, with each column representing the specific study group.

a Years of education starting from primary school through to tertiary education.

TABLE 2 | Means and standard deviations of the demographic variables years of education and age and the total and sub scores of psychopathology scores for the total sample, separate groups and traumatized vs. non-traumatized individuals.

\begin{tabular}{|c|c|c|c|c|c|c|c|c|}
\hline \multirow{2}{*}{$\begin{array}{l}\text { Groups } \\
N=93\end{array}$} & \multicolumn{2}{|c|}{ Total } & \multicolumn{2}{|c|}{$\begin{array}{l}\text { SAD + } \\
(n=40)\end{array}$} & \multicolumn{2}{|c|}{$\begin{array}{c}\text { PTSD } \\
+(n= \\
22)\end{array}$} & \multicolumn{2}{|c|}{$\begin{array}{c}\text { HC } \\
(n=31)\end{array}$} \\
\hline & $M$ & $s d$ & $M$ & $s d$ & $M$ & $s d$ & $M$ & sd \\
\hline LSAS_total & 55.12 & 33.6 & 77.8 & 19.4 & 63.8 & 32.9 & 19.6 & 13.3 \\
\hline LSAS_A & 26.6 & 16.9 & 37.9 & 10.5 & 31.1 & 15.8 & 8.8 & 7.1 \\
\hline LSAS_FA & 28.5 & 17.4 & 39.9 & 10.3 & 32.6 & 17.6 & 10.8 & 7. \\
\hline CTQ_TT & 12.6 & 6.1 & 60.3 & 13.4 & 61.6 & 15.1 & 30.4 & 5. \\
\hline CTQ_EA & 12.6 & 6.0 & 16.3 & 4.1 & 14.6 & 5.8 & 6.3 & 1.7 \\
\hline CTQ_PA & 8.8 & 4.5 & 9.9 & 4.6 & 10.6 & 5.5 & 6.0 & 1.5 \\
\hline CTQ_SA & 8.0 & 4.9 & 8.7 & 5.3 & 9.9 & 5.9 & 5.6 & 1. \\
\hline CTQ_EN & 12.9 & 5.8 & 15.8 & 4.7 & 15.8 & 4.3 & 6.9 & 2.4 \\
\hline CTQ_PN & 8.4 & 3.7 & 9.5 & 3.6 & 10.5 & 3.7 & 5.5 & 1.2 \\
\hline CD_RISC_TT & 66.4 & 18.1 & 58.2 & 17.2 & 60.8 & 15.4 & 80.7 & 11. \\
\hline
\end{tabular}

Total, results of sample as a whole; SAD+, Social anxiety with $C H T$; PTSD+, Posttraumatic stress disorder secondary to CHT; HC, Healthy controls; LSAS-Total, Liebowitz Social Anxiety Scale; LSAS-A, Avoidance subscale total score of the Liebowitz Social Anxiety Scale; LSAS-F, Fear subscale total of the Liebowitz Social Anxiety Scale; CTQ-TT, Childhood Trauma Questionnaire total score; CTQ_EA-,- PA, -SA, -EN, -PN, Childhood Trauma Questionnaire total scores of the subscales. Emotional Abuse, Physical Abuse, Sexual Abuse, Emotional Neglect, and Physical Neglect respectively, CD_RISC_TT, Connor Davidson Resilience Scale total score.

\section{RESULTS}

\section{Total Resilience Score}

A main effect was found for total scores in resilience and group $\left[F_{(2.90)}=21.46, p<0.001, \eta_{p}{ }^{2}=0.32\right]$. Post-hoc analyses revealed that the HC and SAD (mean difference $=22.5$, std error $=3.6$, $p=0.0001$ ), and the HC and PTSD groups (mean difference $=19.8$, std error $=4.2, p=0.0001$ ) differed significantly. The HC group was more resilient than the patient groups. The SAD and PTSD groups did not differ from each other (see Table 3).

TABLE 3 | Bonferroni post-hoc adjustment of ANOVA between groups (PTSD, SAD, Controls).

\begin{tabular}{|c|c|c|c|c|c|}
\hline \multicolumn{2}{|c|}{$\begin{array}{l}\text { Participant group } \\
\text { comparisons }\end{array}$} & \multirow[t]{2}{*}{ Significance } & \multirow[t]{2}{*}{$\begin{array}{l}\text { Mean } \\
\text { difference }\end{array}$} & \multicolumn{2}{|c|}{$\begin{array}{l}\text { 95\% Confidence } \\
\text { interval }\end{array}$} \\
\hline Group 1 vs. & Group 2 & & & $\begin{array}{l}\text { Lower } \\
\text { bound }\end{array}$ & $\begin{array}{l}\text { Upper } \\
\text { bound }\end{array}$ \\
\hline \multirow[t]{2}{*}{ Controls vs. } & SAD & $0.000^{\star \star \star}$ & 22.460 & 13.69 & 31.23 \\
\hline & PTSD & $0.000^{\star \star \star}$ & 19.846 & 9.63 & 30.06 \\
\hline SAD & PTSD & 1.000 & 2.614 & -12.34 & 7.11 \\
\hline
\end{tabular}

TABLE 4 | Bonferroni post-hoc adjustment of ANOVA between groups (PTSD, SAD, Controls).

\begin{tabular}{|c|c|c|c|c|c|}
\hline \multicolumn{2}{|c|}{$\begin{array}{l}\text { Participant group } \\
\text { comparisons }\end{array}$} & \multirow[t]{2}{*}{ Significance } & \multirow[t]{2}{*}{$\begin{array}{l}\text { Mean } \\
\text { difference }\end{array}$} & \multicolumn{2}{|c|}{$\begin{array}{l}95 \% \text { Confidence } \\
\text { Interval }\end{array}$} \\
\hline Group 1 vs. & Group 2 & & & $\begin{array}{l}\text { Lower } \\
\text { bound }\end{array}$ & $\begin{array}{l}\text { Upper } \\
\text { bound }\end{array}$ \\
\hline \multicolumn{6}{|c|}{ CD-RISC FACTOR 1} \\
\hline \multirow[t]{2}{*}{ Controls vs. } & SAD & $0.000^{* \star \star}$ & 6.75 & 3.28 & 10.22 \\
\hline & PTSD & $0.001^{* \star \star}$ & 6.04 & 2.00 & 10.09 \\
\hline SAD & PTSD & 1.000 & 0.71 & -4.56 & 3.14 \\
\hline \multicolumn{6}{|c|}{ CD-RISC FACTOR 2} \\
\hline \multirow[t]{2}{*}{ Controls vs. } & SAD & $0.000^{\star \star \star}$ & 5.23 & 2.43 & 8.03 \\
\hline & PTSD & $0.004^{\star \star}$ & 4.41 & 1.14 & 7.67 \\
\hline SAD & PTSD & 1.000 & 0.82 & -3.93 & 2.28 \\
\hline \multicolumn{6}{|c|}{ CD-RISC FACTOR 3} \\
\hline \multirow[t]{2}{*}{ Controls vs. } & SAD & $0.000^{\star \star \star}$ & 5.04 & 3.24 & 6.83 \\
\hline & PTSD & $0.000^{\star \star \star}$ & 4.80 & 2.71 & 6.88 \\
\hline SAD & PTSD & 1.000 & 0.24 & -2.23 & 1.75 \\
\hline \multicolumn{6}{|c|}{ CD-RISC FACTOR 4} \\
\hline \multirow[t]{2}{*}{ Controls vs. } & SAD & $0.000^{\star \star \star}$ & 3.98 & 2.40 & 31.23 \\
\hline & PTSD & $0.000^{\star \star \star}$ & 3.41 & 1.58 & 30.06 \\
\hline SAD & PTSD & 1.000 & 0.57 & -2.31 & 7.11 \\
\hline \multicolumn{6}{|c|}{ CD-RISC FACTOR 5} \\
\hline \multirow[t]{2}{*}{ Controls vs. } & SAD & $0.018^{*}$ & 1.47 & 0.19 & 2.75 \\
\hline & PTSD & 0.161 & 1.19 & -0.30 & 2.68 \\
\hline SAD & PTSD & 1.000 & 0.28 & -1.69 & 1.14 \\
\hline
\end{tabular}

${ }^{*} p<0.05 ;{ }^{* \star} p<0.01 ;{ }^{* \star *} p<0.001$. 


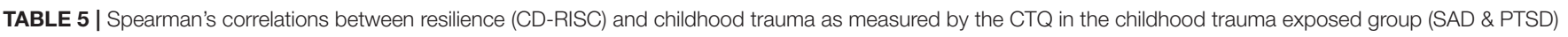
$(n=62)$.

\begin{tabular}{|c|c|c|c|c|c|c|c|}
\hline Variable & $\begin{array}{l}\text { Spearman's rho } \\
\text { (r value) and } p \text {-values }\end{array}$ & $\begin{array}{c}\text { Emotional } \\
\text { abuse (CTQ) }\end{array}$ & $\begin{array}{c}\text { Emotional } \\
\text { neglect (CTQ) }\end{array}$ & $\begin{array}{c}\text { Physical } \\
\text { abuse (CTQ) }\end{array}$ & $\begin{array}{c}\text { Physical } \\
\text { neglect (CTQ) }\end{array}$ & $\begin{array}{l}\text { Sexual abuse } \\
\text { (CTQ) }\end{array}$ & $\begin{array}{l}\text { CTQ-Total } \\
\text { score }\end{array}$ \\
\hline \multirow[t]{2}{*}{ Resilience (CD-RISC) } & $r$-value & 0.110 & -0.137 & 0.036 & 0.264 & 0.185 & 0.149 \\
\hline & $p$-value & 0.396 & 0.287 & 0.779 & 0.038 & 0.149 & 0.248 \\
\hline
\end{tabular}

${ }^{*} p<0.000$.

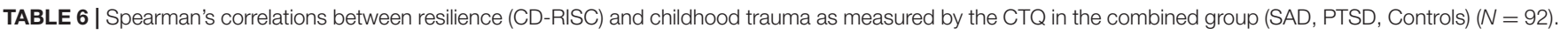

\begin{tabular}{|c|c|c|c|c|c|c|c|}
\hline Variable & $\begin{array}{l}\text { Spearman's rho } \\
\text { ( } r \text {-value) and } p \text {-values }\end{array}$ & $\begin{array}{c}\text { Emotional } \\
\text { abuse (CTQ) }\end{array}$ & $\begin{array}{c}\text { Emotional } \\
\text { neglect (CTQ) }\end{array}$ & $\begin{array}{c}\text { Physical } \\
\text { abuse (CTQ) }\end{array}$ & $\begin{array}{c}\text { Physical } \\
\text { neglect (CTQ) }\end{array}$ & $\begin{array}{c}\text { Sexual abuse } \\
\text { (CTQ) }\end{array}$ & $\begin{array}{l}\text { CTQ-Total } \\
\text { score }\end{array}$ \\
\hline \multirow[t]{2}{*}{ Resilience (CD-RISC) } & $r$-value & -0.358 & -0.482 & -0.220 & -0.166 & -0.060 & -0.371 \\
\hline & $p$-value & $0.000^{*}$ & $0.000^{\star}$ & 0.035 & 0.113 & 0.567 & $0.000^{*}$ \\
\hline
\end{tabular}

${ }^{*} p<0.0083$.

\section{Notion of Personal Competence, High Standards, and Tenacity}

A main effect was found on factor 1 scores of the CD-RISC $\left[F_{(2.90)}\right.$ $\left.=12.45, p<0.001, \eta_{p}{ }^{2}=0.22\right]$. Post-hoc analyses revealed that the $\mathrm{HC}$ and SAD (mean difference $=6.7$, std error $=1.4, p<$ 0.0001 ), and the HC and PTSD groups (mean difference $=6.0$, std error $=1.6, p<0.0001$ ) differed significantly. The HC group was more resilient than the patient groups. The SAD and PTSD groups did not differ from each other (see Table 4).

\section{Trust in One's Instincts, Tolerance of Negative Affect, and Strengthening Effects of Stress}

A main effect was found on factor 2 scores of the CD-RISC $\left[F_{(2.90)}\right.$ $\left.=11.15, p<0.001, \eta_{p}{ }^{2}=0.20\right]$. Post-hoc analyses revealed that the $\mathrm{HC}$ and $\mathrm{SAD}$ (mean difference $=5.2$, std error $=1.1, p<$ 0.0001 ), and the HC and PTSD groups (mean difference $=4.4$, std error $=1.3, p=0.004$ ) differed significantly. The HC group was more resilient than the patient groups. The SAD and PTSD groups did not differ from each other (see Table 4).

\section{Positive Acceptance of Change, and Secure Relationships}

A main effect was found on factor 3 scores of the CD-RISC $\left[F_{(2.90)}\right.$ $\left.=26.94, p<0.001, \eta_{p}{ }^{2}=0.37\right]$. Post-hoc analyses revealed that the $\mathrm{HC}$ and SAD (mean difference $=5.0$, std error $=0.7, p<$ 0.0001 ) and the HC and PTSD groups (mean difference $=4.7$, std error $=0.8, p<0.0001$ ) differed significantly. The HC group was more resilient than the patient groups. The SAD and PTSD groups did not differ from each other (see Table 4).

\section{Control}

A main effect was found on factor 4 scores of the CD-RISC $\left.\left[F_{(2.90}\right)=20.63, p<0.001, \eta_{p}^{2}=0.31\right]$. Post-hoc analyses revealed that the $\mathrm{HC}$ and $\mathrm{SAD}$ (mean difference $=3.9$, std error $=$ $0.6, p<0.0001$ ), and the HC and PTSD groups (mean difference $=3.4$, std error $=0.7, p<0.0001$ ) differed significantly. The HC group was more resilient than the patient groups. The SAD and PTSD groups did not differ from each other (see Table 4).

\section{Spiritual Influences}

A main effect was found on factor 5 scores of the CD-RISC $\left[F_{(2.90)}\right.$ $\left.=4.16, p=0.02, \eta_{p}{ }^{2}=0.08\right]$. Post-hoc analyses revealed that only the $\mathrm{HC}$ and $\mathrm{SAD}$ (mean difference $=1.5$, std error $=0.5, p=0.02$ ), differed significantly. The HC group was more resilient than the SAD group. The SAD and PTSD groups, and the HC and PTSD groups did not differ from each other (see Table 4).

\section{Resilience and Childhood Trauma}

No significant correlation was found between total resilience scores and childhood trauma scores in the childhood trauma (SAD and PTSD) groups (see Table 5). However, in the combined dataset (SAD, PTSD, healthy controls), significant negative correlations were found between resilience scores and the following: emotional abuse ( $p<0.0083 ; r=-0.358)$, emotional neglect $(p<0.0083 ; r=-0.482)$, and total childhood trauma scores $(p<0.0083 ; r=-0.371)$ (see Table 6). We corrected for multiple comparisons using Bonferroni by dividing the $p$-value that we obtained $(0.05)$ by the number of tests $(6)$ that we ran for a particular analysis set. The adjusted $p$-value was set at 0.0083 .

\section{DISCUSSION}

The current study is novel in that it examines the association between childhood trauma and resilience in individuals with PTSD and SAD compared with controls without childhood trauma. Congruent with our primary hypothesis, we found significant differences between PTSD, SAD, and controls respectively. Controls were more resilient compared to both disorder groups. This was true for all resilience factors (higher personal competence, higher standards, and greater reliance on own personal instincts [CD-RISC factor 1]; endurance of negative emotional experiences [CD-RISC factor 2]; more likely to positively accept change and make use of secure relationships when faced with stressors [CD-RISC factor 3]; greater control [CD-RISC factor 4]; greater use of spiritual influences to cope in a crisis [CD-RISC factor 5]). Several retrospective studies indicate that early exposure to trauma is associated in adulthood with an 
increased risk of developing anxiety and stress-related disorders (Kendler et al., 1995; Agid et al., 2000; Heim and Nemeroff, 2001; Spila et al., 2008), including PTSD (Ballenger et al., 2004; Bandelow et al., 2004; Etkin and Wager, 2007; Yehuda et al., 2010) and social anxiety disorder (SAD), (Heim and Nemeroff, 2001; Fossion et al., 2014). In addition, multiple trauma exposures in early life have been linked to increased PTSD symptoms (Collin-Vézina et al., 2011). Simon et al. (2009) hypothesized that childhood trauma (as measured with the total CTQ score) may be associated with less resilience. Specifically, emotional neglect was associated with less resilience in adults with SAD (Simon et al., 2009).

Further contrary to our second hypothesis we found no significant correlation between resilience scores and childhood trauma in the SAD and PTSD groups. When we conducted correlation analyses between resilience scores and childhood trauma in the combined dataset (PTSD, SAD, and controls), several significant negative correlations were found. These correlations were between resilience and the following: emotional abuse, emotional neglect, and total childhood trauma score. Not all individuals who experience childhood adversities develop PTSD, SAD or other psychopathology as adults (Collishaw et al., 2007) and may possess resiliency characteristics that protect them from developing psychopathology. Several factors have been associated with resilience, namely an internal locus of control, a sense of meaning, a strong self-esteem, and good problemsolving skills (Rutter, 1985; Taylor et al., 2000; Masten et al., 2009). In this paper resilience refers to personal competence, high standards, and instincts; capability of enduring negative emotional experiences; positive acceptance of change and secure relationships; control and spiritual influences (Connor and Davidson, 2003). In addition, the experience of childhood trauma in some individuals may contribute to their being less affected by stressors in adulthood (Campbell-Sills et al., 2006). Indeed, childhood trauma may lead individuals to become more resilient, or may enhance "steeliness" to future stressors in adulthood, even if they develop later psychopathology (Rutter, 2007), suggesting that resilience is more than just the counterpart of psychopathology and adversity (Ong et al., 2006).

However, in the face of early life adversity, outcomes can differ significantly from one individual to another (Masten et al., 1999; Hovens et al., 2012). These differences have been shown to be affected by the duration and severity of adversity as well as the timing of positive interventions (Horn et al., 2016). In addition, developmental timing of adversity, especially in infancy and adolescence, can impact differentially on lifelong trajectories of health and wellbeing (Gee and Casey, 2015).

This study adds to our understanding of the role of childhood trauma and resilience in individuals with PTSD, SAD and controls. There has been little comparative investigation of resilience in adults with an anxiety disorder and early childhood trauma exposure, specifically in SAD and PTSD. It is plausible that childhood trauma may interact with the level of resilience in adults with PTSD and SAD. To our knowledge there are no studies that have assessed resilience in PTSD and SAD in the context of childhood trauma. This is important given that resilience, against a background of childhood trauma, may be a modifiable target for treatment recovery in patients with anxiety and stress-related disorders. Reliability coefficients of the CTQ and CD-RISC measurements indicate high internal consistency (Cronbach alphas $\geq 0.85$ ). All CTQ subscales had high Cronbach alphas $(\geq 0.84)$, with the exception of physical neglect for which internal consistency was questionable $(=0.67)$.

A few limitations of this study warrant mention. Firstly, the use of the CD-RISC may be seen as a limitation. The CD-RISC only measures certain aspects of resilience, yet resilience is a complex (multidimensional) construct (Connor and Davidson, 2003). Connor and Davidson (2003) have also pointed out the need for more comprehensive, acceptable and well-validated measures of resilience that are easy to administer. An exploration of the resilience literature points out that there is still much heterogeneity in outcome (Rutter, 2007). The ongoing debate surrounding conceptual issues of resilience such as distinctions between promotive and vulnerability factors, the lack of studies examining gene $\mathrm{x}$ environment interactions, and research focusing on resilience on outcome variables alone instead of underlying processes, should be taken into consideration in future research, and point to the limitations of the present study (Luthar et al., 2006). Furthermore, with regards to positive change or a "steeling effect" following adversity exposure, Brooks et al. (2016) reported that age at event, active coping, PTSD symptom severity and social support may predict a positive vs. a negative change in resilience. In our opinion a more comprehensive assessment of resilience, childhood trauma severity and multiplicity, and other environmental stressors may provide a better understanding of contributory factors that may facilitate or hinder adaptation in individuals with SAD or PTSD. Second, the results of nonparametric correlational analysis should be cautiously interpreted in view of the small sample. Third, the sample was not representative of all ethnic groups in South Africa. Future studies will need to include Black South African and mixed race participants. Lastly, we collected childhood trauma data retrospectively from participants and older participants may have had more difficulty remembering childhood experiences (Spila et al., 2008). That said, it has been suggested that individuals tend to under-report childhood adversities (Hardt and Rutter, 2004).

In conclusion, this study provides preliminary data on the assessment of resilience in SAD and PTSD in the context of childhood trauma. Detailed investigation of resilience in these disorders, in larger samples of patients from different ethnic groups, is needed. Patients who have PTSD and SAD with moderate/severe childhood trauma appear to be significantly less resilient than those with no disorder. Assessing and addressing resilience in these disorders, particularly when childhood trauma is present may facilitate long-term recovery and warrants further investigation.

\section{AUTHOR CONTRIBUTIONS}

MM: Has made substantial contributions to the conception and design, acquisition of data, and analysis and interpretation of 
data. Has been involved in drafting the manuscript and revising it critically for important intellectual content. SY and DR: Has made substantial contributions to the conception and design, acquisition of data, and interpretation of data. Has been involved in revising the manuscript critically for important intellectual content. JH: Has made substantial contributions to the statistical analysis and interpretation of data. Has been involved in revising

\section{REFERENCES}

Agaibi, C. E., and Wilson, J. P. (2005). Trauma, PTSD, and resilience. Trauma. Violence Abuse. 6, 195-216. doi: 10.1177/1524838005277438

Agid, O., Kohn, Y., and Lerer, B. (2000). Environmental stress and psychiatric illness. Biomed. Pharmacother. 54, 135-141. doi: $10.1016 /$ S0753-3322(00)89046-0

American Psychiatric Association (2000). Diagnostic and Statistical Manual of Mental Disorders, 4th Edn. Washington, DC: American Psychiatric Association.

Baker, S., Heinrichs, N., Kim, H., and Hofmann, S. (2002). The Liebowitz social anxiety scale as a self-report instrument: a preliminary psychometric analysis. Behav. Res. Ther. 40, 701-715. doi: 10.1016/S0005-7967(01)00060-2

Ballenger, J. C., Davidson, J. R. T., Lecrubier, Y., Nutt, D. J., Marshall, R. D., Nemeroff, C. B., et al. (2004). Consensus statement update on posttraumatic stress disorder from the international consensus group on depression and anxiety. J. Clin. Psychiatry. 65, 55-62.

Bandelow, B., Torrente, A., Wedekind, D., Broocks, A., Hajak, G., and Rüther, E. (2004). Early traumatic life events, parental rearing styles, family history of mental disorders, and birth risk factors in patients with social anxiety disorder. Eur. Arch. Psychiatry Clin. Neurosci. 254, 397-405. doi: 10.1007/s00406-004-0521-2.

Bernstein, D. P., Ahluvalia, T., Pogge, D., and Handelsman, L. (1997). Validity of the Childhood trauma questionnaire in an adolescent psychiatric population. J. Am. Acad. Child Adol. Psychiatry. 36, 340-348. doi: 10.1097/00004583-199703000-00012

Bernstein, D. P., and Fink, L. (1998). Childhood Trauma Questionnaire: A Retrospective Self-Report: Manual. San Antonio, TX: Psychological Corporation.

Blake, D. D., Weathers, F., Nagy, L. M., Kaloupek, D. G., Klauminzer, G., Charney, D. S., et al. (1990). A clinician rating scale for assessing current and life-time PTSD: The CAPS-1. Behav. Ther. 13, 187-188.

Bonanno, G. A. (2004). Loss, trauma, and human resilience: have we underestimated the human capacity to thrive after extremely aversive events? Am. Psychol. 59, 20-28. doi: 10.1037/0003-066X.59.1.20

Brooks, M., Lowe, M., Graham-Kevan, N., and Robinson, S. (2016). Posttraumatic growth in students, crime survivors and trauma workers exposed to adversity. Pers. Individ. Dif. 98, 199-207. doi: 10.1016/j.paid.2016. 04.051

Campbell-Sills, L., Cohan, S. L., and Stein, M. B. (2006). Relationship of resilience to personality, coping, and psychiatric symptoms in young adults. Behav. Res. Ther. 44, 585-599. doi: 10.1016/j.brat.2005.05.001

Carr, C. P., Martins, C. M., Stingel, A. M., Lengruber, V. B., and Juruena, M. F. (2013). The role of early life stress in adult psychiatric disorders: a systematic Review according to Childhood trauma. J. Ner. Men. Dis. 201, 1007-1020. doi: 10.1097/NMD.0000000000000049

Charney, M. E., and Keane, T. M. (2007). Psychometric analyses of the clinicianadministered PTSD scale (CAPS)-bosnian translation. Cult. Divers. Ethnic Minor. Psychol. 13:161. doi: 10.1037/1099-9809.13.2.161

Collin-Vézina, D., Coleman, K., Milne, L., Sell, J., and Daigneault, I. (2011). Trauma experiences, maltreatment-related impairments, and resilience among child welfare youth in residential care. Int. J. Men. Heal. Addict. 9, 577-589. doi: 10.1007/s11469-011-9323-8

Collishaw, S., Pickles, A., Messer, J., Rutter, M., Shearer, C., and Maughan, B. (2007). Resilience to adult psychopathology following childhood maltreatment: evidence from a community sample. Child Abuse Neglect. 31, 211-229. doi: 10.1016/j.chiabu.2007.02.004 the manuscript critically for important intellectual content. SS: Has made substantial contributions to the conception and design, analysis and interpretation of data. Has been involved in drafting the manuscript and revising it critically for important intellectual content. Provided final approval of the version to be published. All authors have read and approved the final manuscript.

Connor, K. M., and Davidson, J. R. T. (2003). Development of a new resilience scale: the Connor-Davidson resilience scale (CD-RISC). Depress. Anxiety. 18, 76-82. doi: 10.1002/da.10113

Cooney, R. E., Atlas, L. Y., Joorman, J., Eugéne, F., and Gotlieb, I. H. (2006). Amygdala activation in the processing of neutral faces in social anxiety disorder: is neutral really neutral? Psychiatry Res. 148, 55-59. doi: 10.1016/j.pscychresns.2006.05.003

DuMont, K. W., Widom, C., and Czaja, S. J. (2007). Predictors of resilience in abused and neglected children grown-ups: the role of individual and neighbourhood characteristics. Child Abuse Neglect. 31, 255-274. doi: 10.1016/j.chiabu.2005.11.015

Ehlert, U. (2013). Enduring psychobiological effects of childhood adversity. Psychoneuroendocrinology 38, 1850-1857. doi: 10.1016/j.psyneuen.2013.06.007

Etkin, A., and Wager, T. D. (2007). Functional neuroimaging of anxiety: a metaanalysis of emotional processing in PTSD, social anxiety disorder, and specific phobia. Am. J. Psychiatry. 164, 1476-1488. doi: 10.1176/appi.ajp.2007.07030504

Fincham, D. S., Altes, L. K., Stein, D. J., and Seedat, S. (2009). Posttraumatic stress disorder symptoms in adolescents: risk factors versus resilience moderation. Compr. Psychiatry. 50, 193-199. doi: 10.1016/j.comppsych.2008.09.001

Fossion, P., Leys, C., Kempenaers, C., Braun, S., Verbanck, P., and Linkowski, P. (2014). Disentangling sense of coherence and resilience in case of multiple traumas. J. Affect. Disord. 160, 21-26. doi: 10.1016/j.jad.2014.02.029

Gee, D. G., and Casey, B. J. (2015). The impact of developmental timing for stress and recovery. Neurobiol. Stress. 1, 184-194. doi: 10.1016/j.ynstr.2015.02.001

Hardt, J., and Rutter, M. (2004). Validity of adult retrospective reports of adverse childhood experiences: review of the evidence. J. Child. Psychol. 45, 260-273. doi: 10.1111/j.1469-7610.2004.00218.x

Heim, C., and Nemeroff, C. B. (2001). The role of Childhood trauma in the neurobiology of mood and anxiety disorders: preclinical and clinical studies. Biol. Psychiatry 49, 1023-1039. doi: 10.1016/S0006-3223(01)01157-X

Herman, A., Stein, D., Seedat, S., Heeringa, S., Moomal, H., and Williams, D. (2009). The South African Stress and Health [SASH] study: 12 month and lifetime prevalence of common mental disorders. South Afr. Med. J. 99, 339-344.

Himelein, M. J., and McElrath, J. A. V. (1996). Resilient child sexual abuse survivors: cognitive coping and illusion. Child Abuse Negl. 20, 747-758.

Hoge, E. A., Austin, E. D., and Pollack, M. H. (2007). Resilience: research evidence and conceptual considerations for posttraumatic stress disorder. Depress. Anxiety 24, 139-152. doi: 10.1002/da.20175

Horn, S. R., Charney, D. S., and Feder, A. (2016). Understanding resilience: new approaches for preventing and treating PTSD. Exp. Neurol. 284, 119-132. doi: 10.1016/j.expneurol.2016.07.002

Hovens, J. G., Giltay, E. J., Wiersma, J. E., Spinhoven, P., Penninx, B. W., and Zitman, F. G. (2012). Impact of childhood life events and trauma on the course of depressive and anxiety disorders. Acta Psychiatr. Scand. 126, 198-207. doi: 10.1111/j.1600-0447.2011.01828.x

Kaplan, S. J., Pelcovitz, D., and Labruna, V. (1999). Child and adolescent abuse and neglect research: a review of the past 10 years. Part I: physical and emotional abuse and neglect. J. Am. Acad. Child Adolesc. Psychiatry. 38, 1214-1222.

Kendler, K. A., Kessler, R. C., Walters, E. E., Maclean, C., Neale, M. C., Heath, A. C., et al. (1995). Stressful life events, genetic liability and onset of an episode of major depression. Am. J. Psychiatry. 152, 833-842.

Lecrubier, Y., Sheehan, D., Weiller, E., Amorim, P., Bonora, I., Harnett Sheehan, K., et al. (1997). The mini international neuropsychiatric interview (MINI). A short diagnostic structured interview: reliability and validity according to the CIDI. Eur. Psychiatry 12, 224-231. doi: 10.1016/S0924-9338(97)83296-8 
Luthar, S. S., Sawyer, J. A., and Brown, P. J. (2006). Conceptual issues in studies of resilience: past, present, and future research. Ann. N.Y. Acad. Sci. 1094, 105-115. doi: 10.1196/annals.1376.009

Luther, S. S., and Cicchetti, D. (2000). The construct of resilience: implications for interventions and social policies. Dev. Psychopathol. 12, 857-885. doi: 10.1017/S0954579400004156

Masten, A. S. (2001). Ordinary magic: resilience processes in development. Am. Psychol. 56, 227-238. doi: 10.1037/0003-066X.56.3.227

Masten, A. S., Cutuli, J. J., Herbers, J. E., and Reed, M. G. (2009). "Resilience in development," in The Handbook of Positive Psychology, 2nd Edn., eds C. R. Snyder and S. J. Lopez (New York, NY: Oxford University Press), 117-131.

Masten, A. S., Hubbard, J. J., Gest, S. D., Tellegen, A., Garmezy, N., and Ramirez, M. (1999). Competence in the context of adversity: pathways to resilience and maladaptation from childhood to late adolescence. Dev. Psychopathol. 11, 143-169. doi: 10.1037//0003-066X.56.3.227

Nemeroff, C. B. (2004). Neurobiological consequences of Childhood trauma. J. Clin. Psychiatry. 65, 18-28.

Norman, R. E., Byambaa, M., De, R., Butchart, A., Scott, J., and Vos, T. (2012). The long-term health consequences of child physical abuse, emotional abuse, and neglect: a systematic review and meta-analysis. PLoS Med. 9:e1001349. doi: 10.1371/journal.pmed.1001349

Ong, A. D., Bergeman, C. S., Bisconti, T. L., and Wallace, K. A. (2006). Psychological resilience, positive emotions, and successful adaptation to stress in later life. J. Pers. Soc. Psychol. 91, 730-749. doi: 10.1037/0022-3514.91. 4.730

Rutter, M. (1985). Resilience in the face of adversity. Protective factors and resistance to psychiatric disorder. Br. J. Psychiatry, 147, 598-611.

Rutter, M. (1987). Psychosocial resilience and protective mechanisms. Am. J. Orthopsychiatry 57, 316-331.

Rutter, M. (2007). Resilience, competence, and coping. Child Abuse Negl. 31, 205-209. doi: 10.1016/j.chiabu.2007.02.001

Safren, S. A., Heimberg, R. G., Horner, K. J., Juster, H. R., Schneier, F. R., and Liebowitz, M. R. (1999). Factor structure of social fears: the liebowitz social anxiety scale. J. Anxiety Disord. 13, 253-270. doi: 10.1016/S0887-6185(99)00003-1

Sheehan, D. V., Lecrubier, Y., Sheehan, K. H., Amorim, P., Janavs, J., Weiller, E., et al. (1998). The Mini-International Neuropsychiatric Interview (M.I.N.I.): the development and validation of a structured diagnostic psychiatric interview for DSM-IV and ICD-10. J. Clin. Psychiatry. 59, 22-33.

Simeon, D., Yehuda, R., Cunil, R., Knutelska, M., Putman, F. W., and Smith, L. M. (2007). Factors associated with resilience in healthy adults. Psychoneuroendocrinology 32, 1149-1152. doi: 10.1016/j.psyneuen.2007.08.005
Simon, N. M., Herlands, N. N., Marks, E. H., Macini, C., Letamendi, A., Li, A., et al. (2009). Childhood maltreatment linked to greater symptom severity and poorer quality of life and function in social anxiety disorder. Depress. Anxiety. 26, 1027-1032. doi: 10.1002/da.20604

Śpila, B., Makara, M., Kozak, G., and Urbańska, A. (2008). Abuse in childhood and mental disorder in adult life. Child Abuse Rev. 17, 133-138. doi: $10.1002 /$ car.1022

Suliman, S., Mkabile, S. G., Fincham, D. S., Ahmed, R., Stein, D. J., and Seedat, S. (2009). Cumulative effect of multiple trauma on symptoms of posttraumatic stress disorder, anxiety, and depression in adolescents. Compr. Psychiatry. 50, 121-127. doi: 10.1016/j.comppsych.2008.06.006

Taylor, S. E., Kemeny, M. E., Reed, G. M., Bower, J. E., and Gruenewald, T. L. (2000). Psychological resources, positive illusions, and health. Am. Psychol. 55, 99-109. doi: 10.1037/0003-066X.55.1.99

Tusaie, K., and Dyer, J. (2004). Resilience: a historical review of the construct. Holist. Nurs. Pract. 18, 3-8. doi: 10.1097/00004650-200401000-00002

Valentine, L., and Feinauer, L. L. (1993). Resilience factors associated with female survivors of childhood sexual abuse. Am. J. Fam. Ther. 21, 216-224.

Weathers, F. W., Keane, T. M., and Davidson, J. T. (2001). Clinician-administered PTSD scale: a review of the first ten years of research. Depress. Anxiety 13, 132-156. doi: 10.1002/da.1029

Wingo, A. P., Wrenn, G., Pelleteir, T., Gutman, A. R., Bradley, B., and Ressler, J. (2010). Moderating effects of resilience on depression in individuals with a history of childhood abuse or trauma exposure. J. Affect. Disord. 126, 411-414. doi: 10.1016/j.jad.2010.04.009

Wright, M. O., Fopma-Loy, J., and Fischer, S. (2005). Multidimensional assessment of resilience in mothers who are child sexual abuse survivors. Child Abuse Negl. 29, 1173-1193. doi: 10.1016/j.chiabu.2005.04.004

Yehuda, R., Flory, J. D., Pratchett, L. C., Buxbaum, J., Ising, M., and Holsboer, F. (2010). Putative biological mechanisms for the association between early life adversity and the subsequent development of PTSD. Psychopharmacology 7, 1-13. doi: 10.3402/ejpt.v1i0.5467

Conflict of Interest Statement: The authors declare that the research was conducted in the absence of any commercial or financial relationships that could be construed as a potential conflict of interest.

Copyright (c) 2017 Marx, Young, Harvey, Rosenstein and Seedat. This is an openaccess article distributed under the terms of the Creative Commons Attribution License (CC BY). The use, distribution or reproduction in other forums is permitted, provided the original author(s) or licensor are credited and that the original publication in this journal is cited, in accordance with accepted academic practice. No use, distribution or reproduction is permitted which does not comply with these terms. 